This item was submitted to Loughborough's Research Repository by the author.

Items in Figshare are protected by copyright, with all rights reserved, unless otherwise indicated.

\title{
Degradation of interfacial adhesion strength within photovoltaic mini-modules during damp-heat exposure
}

\section{PLEASE CITE THE PUBLISHED VERSION}

http://dx.doi.org/10.1002/pip.2460

\section{PUBLISHER}

John Wiley and Sons Ltd / (c) The Authors

VERSION

VoR (Version of Record)

\section{PUBLISHER STATEMENT}

This is an Open Access article distributed under the terms of the Creative Commons Attribution License (http://creativecommons.org/licenses/by/3.0), which permits unrestricted use, distribution, and reproduction in any medium, provided the original work is properly credited.

\section{LICENCE}

CC BY-NC-ND 4.0

\section{REPOSITORY RECORD}

Wu, Dan, Jiang Zhu, Thomas R. Betts, and Ralph Gottschalg. 2019. "Degradation of Interfacial Adhesion Strength Within Photovoltaic Mini-modules During Damp-heat Exposure". figshare. https://hdl.handle.net/2134/14188. 


\title{
Degradation of interfacial adhesion strength within photovoltaic mini-modules during damp-heat exposure
}

\author{
Dan $\mathrm{Wu}^{*}$, Jiang Zhu, Thomas R. Betts and Ralph Gottschalg \\ Centre for Renewable Energy Systems Technology (CREST), School of Electronic, Electrical and Systems Engineering, Loughborough \\ University, Loughborough, Leicestershire LE11 3TU, UK
}

\begin{abstract}
The degradation of adhesion strength between the back sheet and encapsulant due to moisture penetration has been investigated for commercial crystalline silicon photovoltaic mini-modules. The damp-heat tests originating from the International Electrotechnical Commission qualification test were carried out at five different temperature and relative humidity (RH) conditions $\left(95^{\circ} \mathrm{C} / 85 \% \mathrm{RH}, 85^{\circ} \mathrm{C} / 85 \% \mathrm{RH}, 65^{\circ} \mathrm{C} / 85 \% \mathrm{RH}, 85^{\circ} \mathrm{C} / 65 \% \mathrm{RH}\right.$ and $\left.85{ }^{\circ} \mathrm{C} / 45 \% \mathrm{RH}\right)$. The adhesion strength was measured by $90^{\circ}$ peel tests, carried out at specified time intervals during degradation. Several visible defects were observed, including delamination, moisture ingress and bubble formation. The adhesion strength showed a stretched exponential decay with time, and significant influence of test conditions was demonstrated. A humidity dose model was proposed by assuming micro-climates seen by the modules, that is, surface relative humidity of the back sheet as the driving factor for an Arrhenius-based model using temperature as accelerating factor. The correlation between adhesion strength degradation and humidity dose was investigated through linear and exponential models. Results showed that the conventional linear model failed to represent the relationship while the exponential model fitted to this correlation with extracted activation energy $\left(E_{\mathrm{a}}\right)$ of around $63 \mathrm{~kJ} / \mathrm{mol}$. This provides a model for the estimation of adhesion strength decay in dependence of the humidity conditions. (C) 2014 The Authors. Progress in Photovoltaics: Research and Applications published by John Wiley \& Sons, Ltd.
\end{abstract}

\section{KEYWORDS}

adhesion strength; damp heat; peel test; humidity dose

* Correspondence

Dan Wu, Centre for Renewable Energy Systems Technology (CREST), School of Electronic, Electrical and Systems Engineering, Loughborough University, Loughborough, Leicestershire LE11 3TU, UK.

E-mail: D.Wu@|boro.ac.uk

This is an open access article under the terms of the Creative Commons Attribution License, which permits use, distribution and reproduction in any medium, provided the original work is properly cited.

Received 30 June 2013; Revised 24 November 2013; Accepted 27 November 2013

\section{INTRODUCTION}

Good encapsulation is required for photovoltaic (PV) modules to ensure reliability and lifetime. Field inspections have shown that encapsulation-related degradation is a key failure mode for PV systems [1]. The active PV material is usually encapsulated by a front cover (usually glass), polymeric encapsulant, back sheet and edge seal [2]. The different components are bonded adhesively to each other. These form a multilayer system that ensures the safety and to some extent the performance of the module by protecting PV cells from the environment, but also results a high number of interfaces. These interfaces are potential paths for contaminant ingress and leakage current and thus are potential sources for arcing [3]. Delamination can also happen within these interfaces, which has been observed in field-exposed PV systems [4-6]. Delamination reduces the efficiency of the moisture barrier and results in further degradation mechanisms such as corrosion of metallic components, polymer decomposition, light transmission losses and reduction of resistance of the encapsulant $[7,8]$. The delaminated area will also suffer from reduced heat dissipation, which has the potential to cause thermal fatigue and hot spotting [1]. Therefore, the strength of these bonds is crucial for the module reliability and is the topic of this paper. It will be shown that de-bonding of the back sheet occurs at the interface between the encapsulant and back sheet (rather than breaking of the encapsulant), and thus, the focus of this paper is on this particular interface. 
The loss of adhesion strength is expected to vary with the operating environment, depending on factors of temperature, humidity and irradiance including ultraviolet (UV). The long-term aim of this work is to model this behaviour, to predict lifetime durability of PV modules and to optimise module design for longevity. This requires the superposition of a number of different ageing mechanisms that may or may not act independently. Each of these effects needs to be investigated in isolation before an overall model can be derived. This paper concentrates on the adhesion reliability of the interface between the encapsulant and back sheet to withstand the effects of moisture penetration as influenced by temperature. The objective is to understand the effects of sustained steady state stresses of humidity and temperature on the back sheet adhesion. In standard qualification testing, this is carried out through the damp-heat test, where modules are exposed to a relative humidity of $85 \%$ at a temperature of $85^{\circ} \mathrm{C}[9,10]$. This test is designed to drive humidity into any kind of encapsulated PV modules to benchmark basic survivability but is not per se designed to test the lifetime of an encapsulation. An underlying assumption is that the external humidity is higher than the equivalent chemical potential of water in the packaging, which means the direction of humidity migration is from the external environment into the packaging. If the direction of water is reversed, that is, the moisture within packaging is dried out into the atmosphere, a different potential failure mode is triggered, and the damp-heat test loses its validity. The focus of this paper is on the damp-heat test and how different conditions influence the loss of adhesion due to moisture ingress. The direction of moisture migration of the damp-heat tests represents most of the outdoor conditions but in accelerated rates and lager amount. Outdoor exposure normally involves other combined complex stress conditions, and the results of the damp-heat tests can only reflect part of the degradation in outdoor exposure.

Moisture can influence the adhesion strength in several different ways. Today, ethylene vinyl acetate (EVA) is the most commonly used encapsulant in the PV industry. Normally, the encapsulation is carried out using sheets of EVA that contain a complex cocktail of additives to the EVA resin to enhance its performance. One of the additives is an adhesion promoter, normally in the form of silane coupling agents that are used to enhance adhesion between EVA and glass by forming silicon-oxygen covalent bonds [11]. For the adhesion between EVA and the back sheet, coupling agents or primers are often added at the inner side of the back sheet to enhance the adhesion by either forming chemical bonds or increasing physical adsorption. Moisture attack has the risk of causing bond decomposition depending on the format of the bond, which in turn leads to reduced adhesion strength. Such a de-bonding reaction is normally accelerated by temperature. In addition, because of the high permittivity of water, the presence of moisture will weaken the potential energy of ionic attraction and also reduce the physical adsorption force across the interface (van der Waals forces), which is especially important for high polarity adherend [12]. These forces are inversely proportional to the relative permittivity of the medium. At room temperature, the typical relative permittivity (the ratio of the absolute permittivity of the material to that of the vacuum) of polyethylene terephthalate (PET) with a thickness of $5-50 \mu \mathrm{m}$ is around 2.5-4.5 while it is 80 for water, which means a small amount of water will lower the force significantly [13]. Besides, the high polarity of water results a high surface tension that helps reduction of the thermodynamic work of adhesion and thus lowers the durability of the interface [14]. In general, moisture ingress into a polymer is accelerated by temperature $[15,16]$. In this context, for the damp-heat test, an assumption can be made that the loss of adhesion strength is primarily induced by moisture and that temperature itself is not a stress factor but acts as an accelerator of the effects of humidity.

Temperature itself affects the device more in a mechanical way by means of differential thermal expansion. This would be seen in real life because of daily and seasonal thermal cycles and can be emulated in stress chambers by thermal cycling tests. However, these considerations are outside the scope of this paper that focuses on steady state stresses as mentioned earlier. There are also a number of additional potential failure mechanisms that will have to be considered in the development towards a full degradation model. These are acknowledged but would detract from the main theme of the paper and are thus not considered here.

There are a number of published studies of adhesion strength for PV modules. Some of them report reduced adhesion but methodologically are normally based on progressive uncontrolled ageing or carried out at a single controlled operating condition. Jorgensen and McMahon [17] measured the peel strength of different interfaces within thin film PV modules of various technologies and structures before and after damp-heat conditioning, and under ultraviolet light. Non-uniform reduction of adhesion strength was observed at different interfaces, and they suggested that tests at higher temperature and relative humidity levels were preferred to screen modules. At National Renewable Energy Laboratory, extensive peel tests were conducted to understand the factors influencing the adhesion strength of EVA to glass substrates, including EVA type and formulation, backfoil type and manufacturing source, glass type, surface cleaning methods and surface priming treatment [18]. Pern and Jorgensen [19] investigated the adhesion strength between glass and EVA and its resistance to damp-heat exposure by developing different primer formulations for EVA. Enhanced adhesion strength was observed for laminates with EVA having high density siloxane primers. Although increasing concern is given to adhesion issues, there have been few reliability tests and quantitative degradation studies. The degradation pattern of adhesion strength is not established for these layers, and the numerical correlation to environmental stresses such as temperature and humidity is currently largely being postulated. 
This paper presents an approach that allows the measurement of degradation of adhesion strength between the back sheet and encapsulant for PV modules and develops modelling methods for the correlation of adhesion strength degradation with environmental humidity and temperature levels. Well-controlled peel tests were used to measure the adhesion strength at certain time intervals during device exposure to different damp-heat conditions. As this research only focuses on humidity-induced degradation, neither dry condition nor extremely high temperature levels are considered, because these may introduce different failure mechanisms. The degradation of adhesion strength with time is assessed, and the correlation between degradation and environmental stresses of humidity and temperature is also investigated through both conventional linear and extended exponential degradation models.

\section{EXPERIMENTAL DESIGN}

The aim of the experiment is to investigate the degradation of adhesion strength between the back sheet and encapsulant with exposure to high humidity (relative to residual humidity within the sample) and understand the acceleration rates of different stress levels. This requires exposure of samples to different temperature and humidity levels and the measurement of the adhesion strength after certain time intervals. The different stress levels were achieved by multiple environmental chambers set up at different conditions. The adhesion strength was measured with a destructive $90^{\circ}$ peel test for which samples can only be used a single time. Multiple samples were thus required, which would introduce some sample-to-sample variations, and to minimise this, samples produced by a single manufacturer only were used.

The samples used in this work are commercial frameless small area laminates with polycrystalline silicon solar cells inside. These laminates have no edge seal that accelerates the overall humidity ingress compared with laminates protected by edge seal. The laminate size is $140 \mathrm{~mm}$ by $100 \mathrm{~mm}$ in length and width. The encapsulant material is EVA, and the back sheet is double layers of PET that were verified by Fourier transform infrared spectrometer test. The thicknesses of the EVA sheet and the back sheet are approximately 400 and $250 \mu \mathrm{m}$, respectively, which were measured by microscope. Indoor accelerated damp-heat tests were conducted in environmental chambers at five different conditions as listed in Table I. The testing time and number of modules at each condition

Table I. Testing conditions for photovoltaic modules.

\begin{tabular}{lccc}
\hline & \multicolumn{3}{c}{$R H$} \\
$T\left({ }^{\circ} \mathrm{C}\right)$ & $85 \%$ & $65 \%$ & $45 \%$ \\
\hline 95 & $\checkmark$ & & \\
85 & $\checkmark$ & $\checkmark$ & $\checkmark$ \\
65 & $\checkmark$ & & \\
\hline
\end{tabular}

are shown in Figure 1. A number of trial tests were carried out at $85^{\circ} \mathrm{C} / 85 \% \mathrm{RH}$ to roughly qualify the module, and the test points were chosen according to the data collected there. It was found that the adhesion strength became $2-3 \mathrm{~N} / \mathrm{cm}$ after around only $100 \mathrm{~h}$ exposure. Therefore, in general, daily measurements were carried out.

The back sheet of each module was cut by $\mathrm{CO}_{2}$ laser into strips of $10 \mathrm{~mm}$ width (i.e. 10 strips along the long edge of the modules) once the intended stress level was reached. An automated laser cut was used. The cutting speed was set to $762 \mathrm{~mm} / \mathrm{s}$ with a power of $32 \mathrm{~W}$ and 10 passes to achieve the desired cutting depth. Laser cut has many advantages compared with other alternative cutting methods such as blade or disc-based cutting. The quality of the cuts is shown in Figure 2, which presents an image of one of the typical strip cuts measured by a coherence correlation interferometer. The left figure is the 3-D image of the surface profile near the cut while the right one is the corresponding 2-D image. The colour scale indicates the depth of the scanned surface. The trench in Figure 2(a) is the cut. A depth of $250 \mu \mathrm{m}$ is observed, which equals to the thickness of the back sheet (roughly $250 \mu \mathrm{m}$ ). Compared with commonly used blade cutting, laser cutting is a quick and precise cutting method with accurate control of cutting depth, ensuring little damage of the encapsulant layer and also guaranteeing parallel cutting. Each of the peel strips was $10 \mathrm{~mm}$ in width and $100 \mathrm{~mm}$ in length. The first $15 \mathrm{~mm}$ of each strip was disregarded because it was peeled off before testing to form a tab so that the grip of the peel test machine could be secured to hold the strip.

Each of the strips was then peeled off using a $90^{\circ}$ peel test set-up with a crosshead speed of $50 \mathrm{~mm} / \mathrm{min}$ at ambient room temperature. The test was conducted based on standard BS EN ISO 8510 [20]. The peel test is very sensitive to environment, sample and testing conditions, and thus requires a large number of tests to ensure sufficient accuracy and good averaging. A total of 20-30 strips from two to three different modules were examined on average for each condition at each measurement point (Figure 1). A visual inspection was also carried out after removal of the modules from the environmental chambers, prior to the laser cutting.

\section{EXPERIMENTAL RESULTS}

\subsection{Visual inspection}

Several types of visual defects were seen during ageing. Some of the more severe ones are depicted in Figure 3. Delamination was observed, mostly at corners and edges of the mini-module. The lack of edge seal of the module left the edge directly open to the environment where stronger influences were seen compared with those areas with an effective moisture barrier. Imperfect lamination may also contribute to the developing fault. Moisture penetration into the module was also observed and bubbles appeared at the front glass/EVA interface. After $24 \mathrm{~h}$ ageing at $95^{\circ} \mathrm{C} / 85 \% \mathrm{RH}$, a large bubble around the 


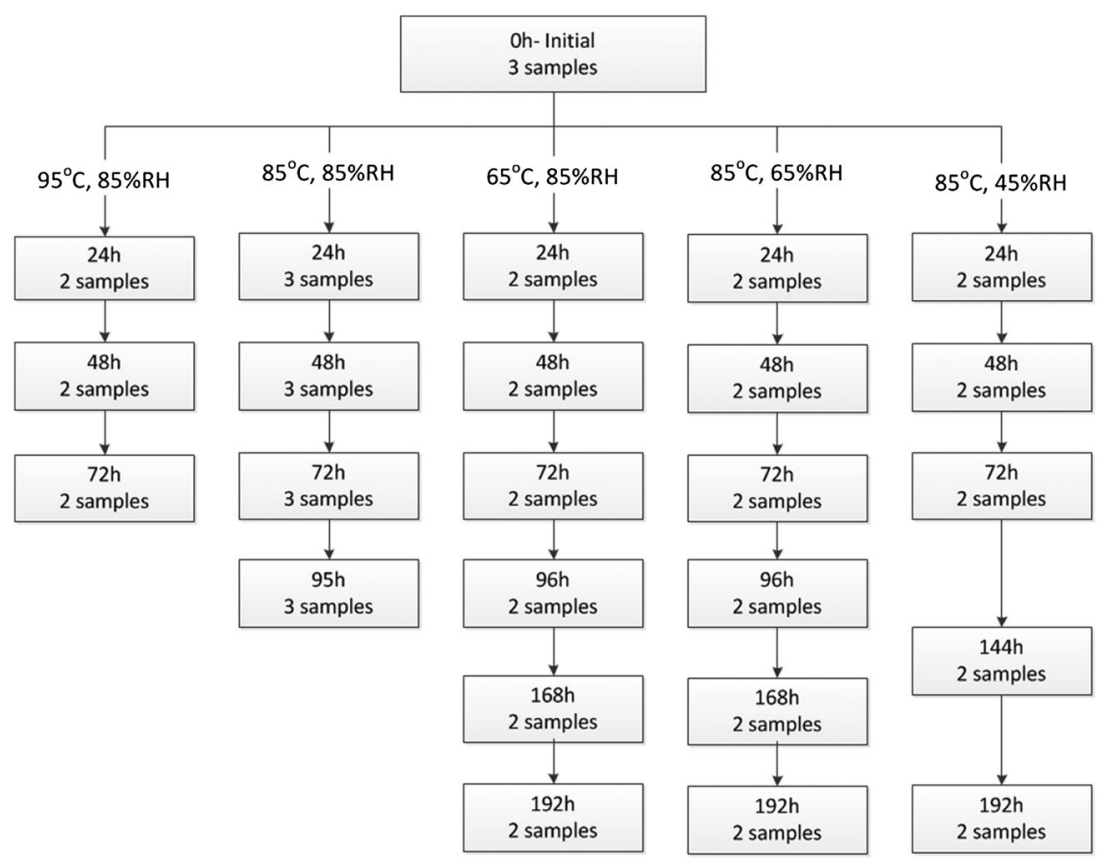

Figure 1. Flow chart of testing time and number of samples for each degradation condition.

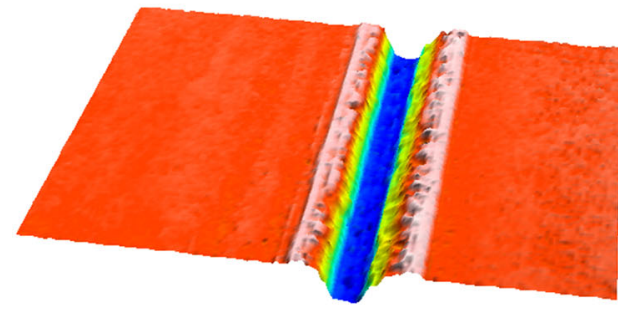

(a)

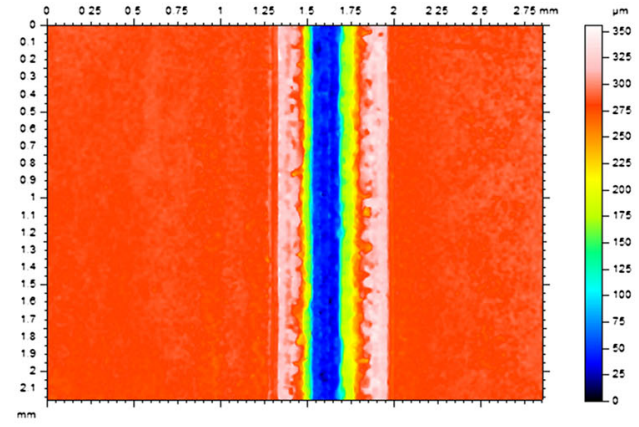

(b)

Figure 2. Interferometer image of the cutting of the back sheet. (a) 3-D image of the peel strip cutting and (b) 2-D image of the peel strip cutting.

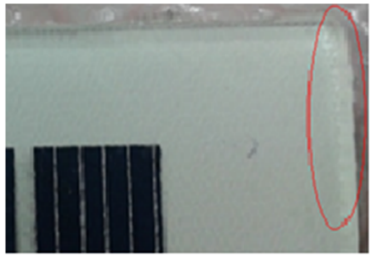

(a)

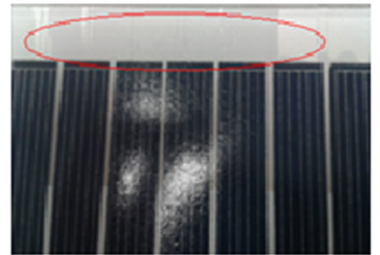

(b)

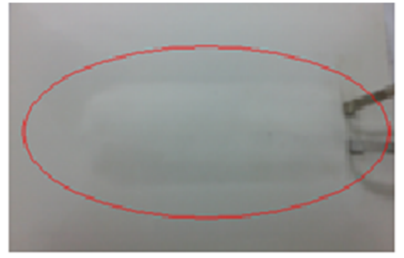

(c)

Figure 3. Defects observed after damp-heat testing: (a) edge/corner delamination, (b) moisture ingress and (c) bubble near electrode exit.

electrodes was observed. This is due to the poor protection around the external contacts where an access cut in the back sheet is not well sealed, allowing water vapour ingress. The majority of the module would have passed visual inspection.

\subsection{Peel test results}

The peel test measures the fracture energy required to separate the surfaces of the interface as a function of peel time or the equivalent displacement. The separation can 
happen either at the interface or in the bulk of a material (cohesive failure) if the structural integrity is weaker than the bonding strength at the interface. This was checked visually and by taking microscopic photos at the surface of the inner side of back sheet. An example is shown in Figure 4, which presents the surface microscopic image of one of the peeled PET strips after $48 \mathrm{~h}$ degradation at $85^{\circ} \mathrm{C} / 85 \%$ RH. No EVA is seen attached on this

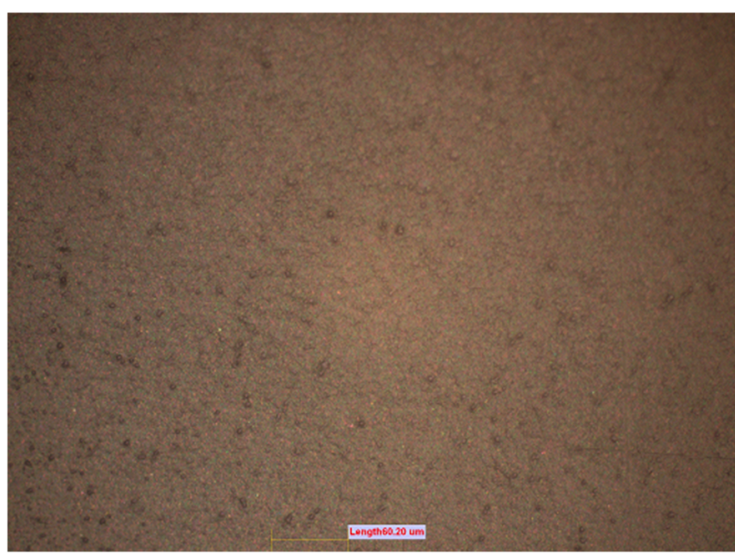

Figure 4. Microscopic image of the surface of the inner side of the back sheet for modules exposed at $85^{\circ} \mathrm{C} / 85 \% \mathrm{RH}$ after $48 \mathrm{~h}$ degradation (magnification 10x). surface, which indicates that the failure mechanism is interfacial rather than cohesive and the measured adhesion strength is that of the interface between the back sheet and encapsulant.

A typical result of the peel test can be seen in Figure 5. Three stages can be defined as follows:

(1) Loading of the peeling arm as it takes up slack. The pull force increases until the strip is fully tensioned to the peel tip where peeling starts.

(2) Propagation of the interface separation. Data from this area give the adhesion strength sought. In this study, the first $1 \mathrm{~cm}$ after tensioning was discarded, as the adhesion strength was not reliably measurable in this region. Data of the last $2 \mathrm{~cm}$ also were not used, as the silicon cell of the module ended $1 \mathrm{~cm}$ before the edge of the module. A further $1 \mathrm{~cm}$ at the end side was excluded to eliminate variation caused by the tolerance of the size of the silicon cell. The average value of the remaining data was used for the degradation study.

(3) Completion of the separation. A sudden drop of the peel strength to 0 is characterised in this stage.

The measured peel strength is module dependent. The variation over some of the measured strips is smaller while larger for others. An example is given in Figure 5 where the top figure fluctuates significantly,

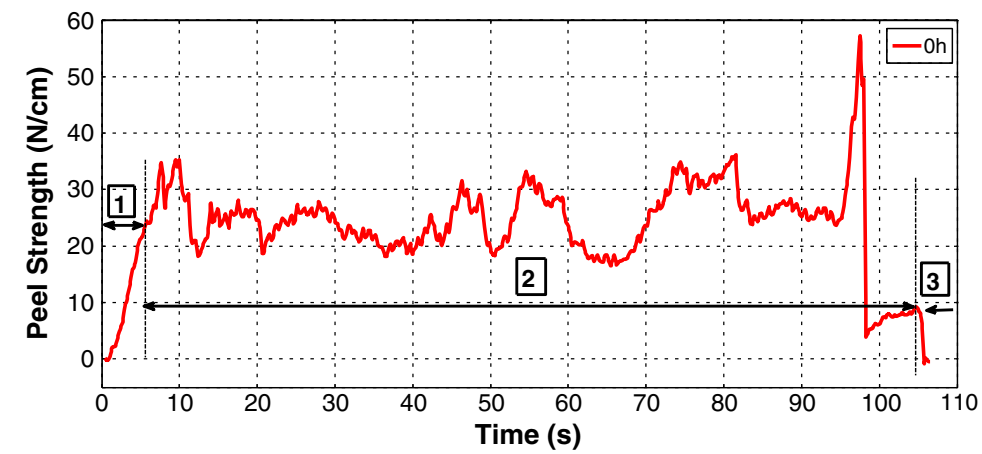

(a) Peel test data for a strip of one of the un-aged modules

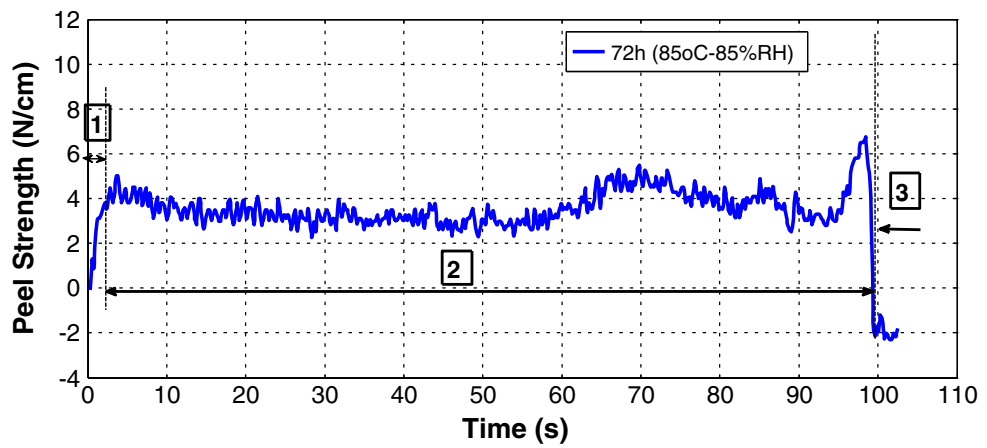

(b) Peel test data for a strip of one of the modules after $72 \mathrm{~h}$ degradation at $85^{\circ} \mathrm{C} / 85 \% \mathrm{RH}$

Figure 5. Typical peel test results. 
and the plot of the bottom figure is relatively flat. Such variations may result from factors such as the variations in manufacturing process of the material and imperfect lamination quality due to uneven temperature and pressure distribution etc.

\subsection{Degradation of adhesion strength with time}

Adhesion strengths are plotted against stress exposure time in Figure 6 for all the conditions listed in Table I of $95^{\circ} \mathrm{C} / 85 \%$ $\mathrm{RH}, 85^{\circ} \mathrm{C} / 85 \% \mathrm{RH}, 65^{\circ} \mathrm{C} / 85 \% \mathrm{RH}, 85^{\circ} \mathrm{C} / 65 \% \mathrm{RH}$ and $85^{\circ} \mathrm{C} / 45 \% \mathrm{RH}$. The adhesion strength under different conditions shows similar degradation pattern in the form of a stretched exponential decay. The adhesion strength decreases quickly at the beginning and then tends to slow down after a certain time. Increased humidity accelerates the loss of adhesion. Temperature further enhances the effect of humidity at a faster rate. In general, the reduction of the adhesion strength is rather quick, but this can be attributed to the high stress levels and the absence of edge seal in these particular samples. The small sample size of $0.012 \mathrm{~m}^{2}$, which is about $1-2 \%$ of a normal commercial module size, further increases humidity uptake. All of these factors increased acceleration achieved in the tests; however, the principles of degradation remained unchanged.
The adhesion strength with degradation time under different conditions can be fitted by the following equation:

$$
S_{t}=S_{0} e^{-\left(\frac{t}{t_{d e l}}\right)^{\beta}}
$$

where $t$ is the degradation time, $S_{0}$ is the adhesion strength before degradation (i.e. at $t=0$ ), $S_{t}$ is the adhesion strength at time $t, \beta$ and $t_{d e l}$ are two parameters controlling the slope and tail of the degradation curves. The parameter $t_{d e l}$ primarily determines the slope of the degradation, and $\beta$ represents the magnitude of the influence of $t_{d e l}$. The overall behaviour of the degradation depends on the combination of $t_{d e l}$ and $\beta$. The fitted values of $t_{d e l}$ and $\beta$ for each condition can be seen in Table II. Different stress conditions have different values of $t_{d e l}$ and $\beta$. Therefore, the prediction of adhesion strength reduction with time based on Eqn (1) requires additional modelling of the dependence of $t_{d e l}$ and $\beta$ on stress levels and duration. An alternative simplified solution would be to determine a parameter that enables the modelling of adhesion degradation with this single variable. This is discussed later in the paper.

Also listed in Table II are the degradation rates $\left(R_{D}\right)$ calculated from experimental data (average $R_{D}$ for each condition) and the corresponding acceleration rates. The

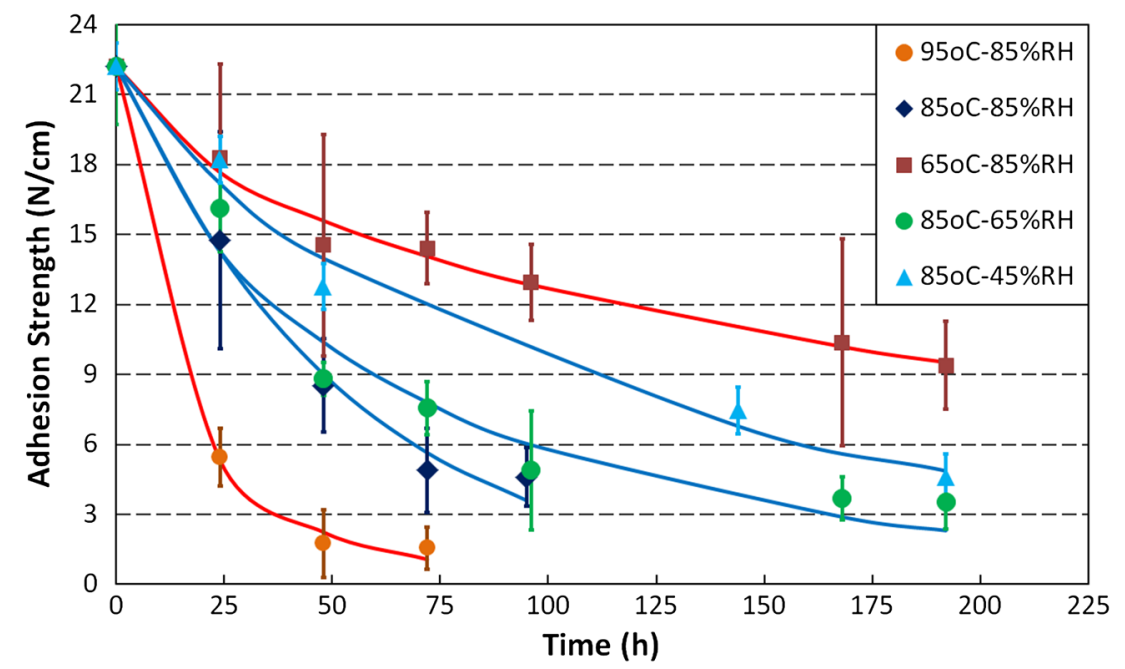

Figure 6. Reduction of peel strength in dependence of applied stresses and time.

Table II. Parameters for the adhesion strength degradation.

\begin{tabular}{lrccc}
\hline Conditions & $t_{d e l}$ & $\beta$ & Experiment $R_{D}(\%)$ & Acceleration rate \\
\hline $65^{\circ} \mathrm{C} / 85 \% \mathrm{RH}$ & 250 & 0.63 & 11.08 & 1 \\
$85^{\circ} \mathrm{C} / 85 \% \mathrm{RH}$ & 53 & 1.03 & 25.53 & 2.3 \\
$95^{\circ} \mathrm{C} / 85 \% \mathrm{RH}$ & 14 & 0.69 & 56.20 & 5.1 \\
$85^{\circ} \mathrm{C} / 65 \% \mathrm{RH}$ & 68 & 0.79 & 20.5 & 1.9 \\
$85^{\circ} \mathrm{C} / 45 \% \mathrm{RH}$ & 118 & 0.86 & 13.93 & 1.3 \\
\hline
\end{tabular}


degradation rate is defined as the percentage adhesion strength decline over time:

$$
R_{D}=\frac{S_{0}-S_{t}}{t} \times 100 \%
$$

The degradation rate at $65^{\circ} \mathrm{C} / 85 \% \mathrm{RH}$ is the lowest while that at $95^{\circ} \mathrm{C} / 85 \% \mathrm{RH}$ is the highest. If taking the lowest degradation at $65^{\circ} \mathrm{C} / 85 \% \mathrm{RH}$ as the baseline, one to five times acceleration rates (the ratio of the degradation rates at different conditions) were observed for the other four conditions. Lower stress levels (lower temperature and lower humidity) cause lower degradation up to a point. The stress levels chosen here are somewhat arbitrary based on qualification test standards but give an indication of the acceleration rates in this set of experimental conditions. Once the applied ambient humidity is low enough, the direction of moisture flow will change from ingress into PV modules to drying out of the module. This is likely to cause different degradation effects, and thus, it is not possible to extrapolate the adhesion degradation behaviour observed in this study to very low humidity conditions.

The adhesion strength shown in Figure 6 is the average values for the entire module (i.e. the averaged measurements from the full lengths of all peel strips) at each testing point. They do not give any indication of variations across the module. An impression of this variation can be obtained by aligning all peel tests for one module side by side to create a contour plot. This spatial profile gives an insight of how the adhesion strength varies over the surface of a module and how it changes over time under stress. Figure 7 is an example of the contour plots showing the development of adhesion strength at $65^{\circ} \mathrm{C} / 85 \% \mathrm{RH}$ with an un-aged module and three modules stressed for 24,72 and $192 \mathrm{~h}$. The $x$-axis represents the strip number with each strip in $10 \mathrm{~mm}$ width, and the $y$-axis is the distance from the peeling end in millimetre, that is, the length of strips. The colour scale of the contour plots demonstrates the adhesion strength in Newton per centimetre, and the blank areas at corners and edges indicate null data where the strips snapped during the peel.

As shown in Figure 7, the peeling of all strips started close to the distance of $85 \mathrm{~mm}$ and ended at the $0 \mathrm{~mm}$ point. The first $15 \mathrm{~mm}$ (not shown) was peeled off before the actual test to create the peeling tab for the machine to seize. Large spikes were observed more often near $10 \mathrm{~mm}$ because that is where the silicon cells end, and although it was checked that the peeling still progressed over the EVA-back sheet interface, the sudden change of the substrate resulted in higher adhesion values. Before degradation, the edges of the modules had lower adhesion strength than the centres. Possible explanations are poor quality lamination at the edge or the open edge of the modules being more influenced by the environment so that some degradation occurred. In general, the adhesion
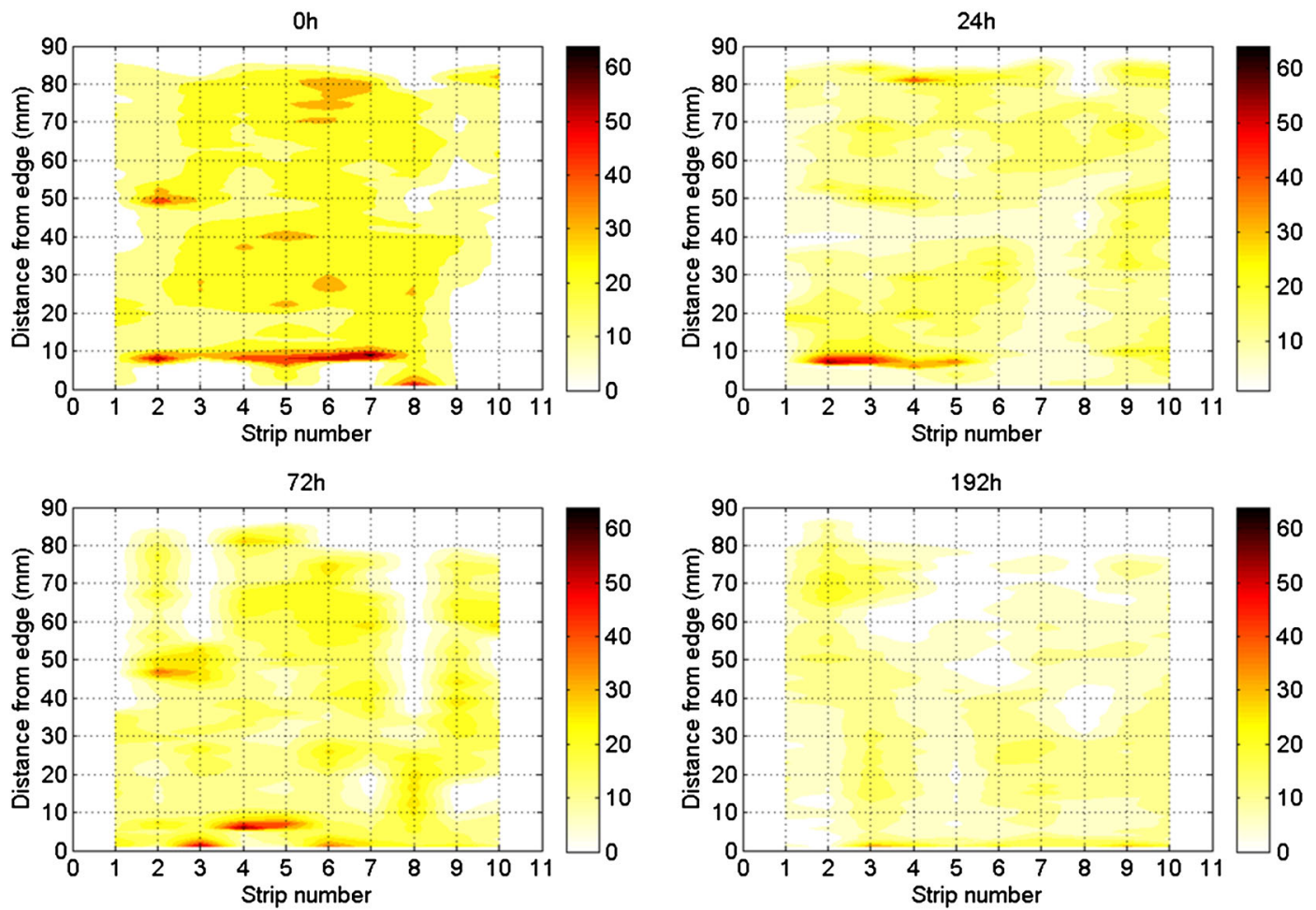

Figure 7. Contour plots of the measured adhesion strength over the module surface for the un-aged module (top left) and modules aged after 24 (top right), 72 (bottom left) and $192 \mathrm{~h}$ (bottom right) at $65^{\circ} \mathrm{C} / 85 \% \mathrm{RH}$ condition (each strip is of $10 \mathrm{~mm}$ width). 
strength reduced as the modules degraded. Several more peaks in adhesion strength existed at different locations before degradation but gradually disappeared throughout stress exposure and became more evenly distributed. Although from this contour map it is not easy to define a precise degradation pattern, it presents the spatial distribution of adhesion strength across the surface of the whole module, which could be helpful for the identification of the statistically weakest spots in a production batch and to some extent the degradation mechanisms. The $24 \mathrm{~h}$ image shows two perpendicular lines with low adhesion strength, where it appears that water 'channelled' into the mini-module. The 72 and $192 \mathrm{~h}$ images seem to show a reduction of the adhesion strength from the inside to the outside. It appears that moisture accumulated in the centre while released around the outside, enabling moisture desorption from these areas.

In order to see the chemical changes of the back sheet during degradation, attenuated total reflection Fourier transform infrared spectroscopy tests of the inner side of the back sheet were conducted. Examples of the results are shown in Figures 8 and 9. Figure 8 shows the normalised attenuated total reflection spectrum of the back sheet by presenting the spectrum of the eighth strip of the samples shown in Figure 7 that degraded at $65^{\circ} \mathrm{C} / 85 \%$ $\mathrm{RH}$ for 0,72 and $192 \mathrm{~h}$ within the spectral band 600 to $1900 \mathrm{~cm}^{-1}$. Some of the main absorption bands observed are listed in Table III [21-23]. Absorption at $1410 \mathrm{~cm}^{-1}$ was used as reference. The normalised average band strength of all the 10 strips for each of the three samples at $1710 \mathrm{~cm}^{-1}(\mathrm{C}=\mathrm{O}$ band of ester $)$ and $1340 \mathrm{~cm}^{-1}$ (crystallinity band) are shown in Figure 9. No obvious changes of the ester and crystallinity groups were observed indicating that the back sheet had not experienced too much chemical degradation, although its adhesion strength with EVA had degraded by around 58\%. Therefore, the interface between EVA and the back sheet is much more affected than the bulk material.

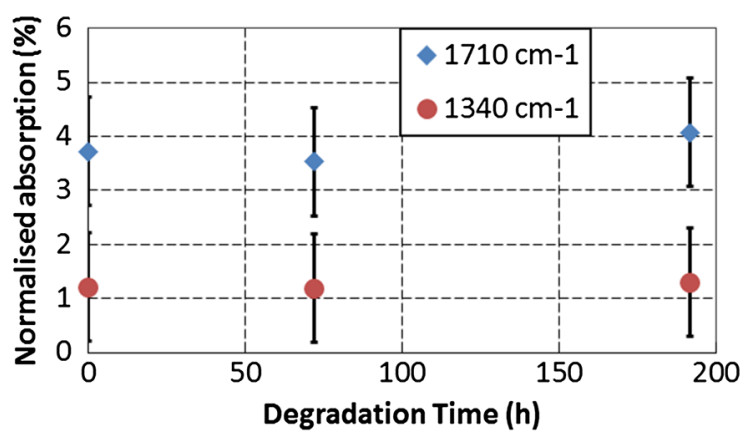

Figure 9. Normalised absorption of the inner back sheet during degradation at $65^{\circ} \mathrm{C} / 85 \% \mathrm{RH}$ : band at $1710 \mathrm{~cm}^{-1}$ represents the $\mathrm{C}=\mathrm{O}$ stretching of ester, band at $1340 \mathrm{~cm}^{-1}$ shows the evolution of crystallinity of polyethylene terephthalate and band at $1410 \mathrm{~cm}^{-1}$ is used as reference.

Table III. Main vibration of polyethylene terephthalate.

\begin{tabular}{ll}
\hline Wave number $\left(\mathrm{cm}^{-1}\right)$ & \multicolumn{1}{c}{ Vibration mode } \\
\hline 1410 & Reference \\
$1701,1242,1096$ & Ester $\mathrm{C}=\mathrm{O}$ stretching \\
1471 & $-\mathrm{CH}_{2}$ twisting \\
1340 & $-\mathrm{CH}_{2}$ wagging \\
1017 & In-plane vibration of benzene \\
870,723 & Out-of-plane vibration of benzene \\
1043,970 & $-\mathrm{C}-\mathrm{O}$ Stretching of glycol \\
897,791 & $-\mathrm{CH}_{2}$ rocking \\
\hline
\end{tabular}

\section{MODELLING DEGRADATION OF ADHESION STRENGTH IN DEPENDENCE OF HUMIDITY AND TEMPERATURE}

\subsection{Stress model development}

The degradation of adhesion strength is investigated by correlating the degradation rates with environmental stresses. In

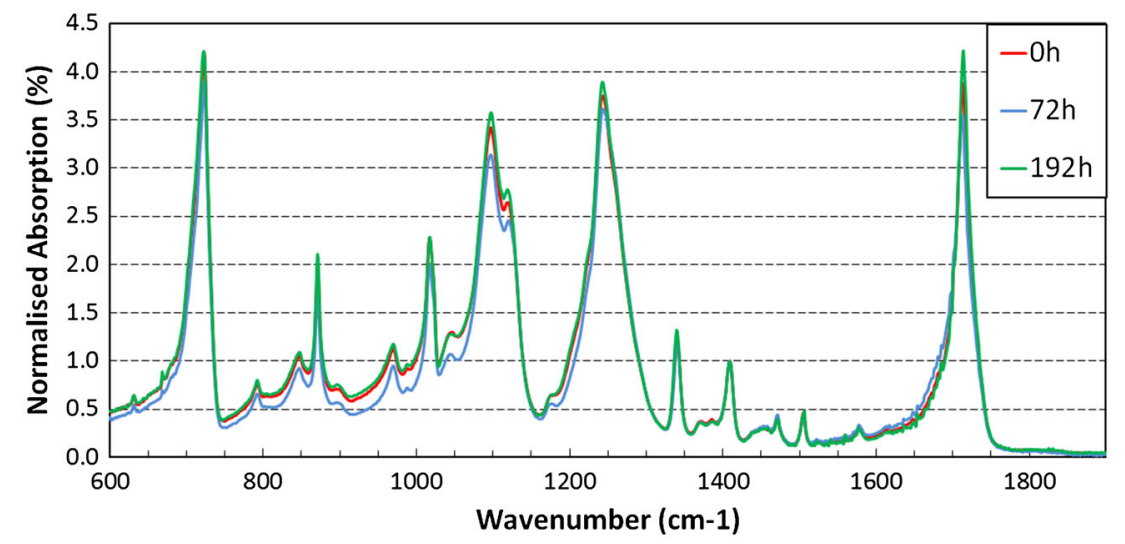

Figure 8. Normalised attenuated total reflection spectra of the eighth strip of the inner back sheet of the un-aged sample and those aged for 72 and $192 \mathrm{~h}$ at $65^{\circ} \mathrm{C} / 85 \% \mathrm{RH}$ (the band at $1410 \mathrm{~cm}^{-1}$ is used as reference). 
order to describe the stresses acting on the modules over a certain period of time, the ambient macro climate, that is, the relative humidity measured at ambient temperature, must be translated to module micro-climate, that is, the relative humidity at the surface of the back sheet at the module temperature. In field deployment under irradiation, the PV module operating temperature is higher than ambient air temperature. This means that the relative humidity experienced by the device is lower than the ambient humidity. There are different published models that can be used to predict module temperature from ambient temperature [24-26]. The standard damp-heat tests in environmental chambers, as presented here, are different in this respect because the device temperature is equal to ambient temperature; that is, module temperature $\left(T_{m}\right)$ is identical to chamber air temperature $\left(T_{a}\right)$. This difference needs to be considered when attempting to predict a service lifetime for an outdoor installation.

The micro-climatic relative surface humidity at the back sheet for outdoor exposure is calculated as shown in Eqns (3) and (4) using the model proposed by Koehl et al. [27]. This assumes that the surface of back sheet is in thermodynamic equilibrium with the atmosphere, and the temperature is uniform across the module:

$$
\begin{gathered}
R H_{a}=\frac{P_{w}}{P_{s}\left(T_{a}\right)} \\
R H_{m}=\frac{P_{w}}{P_{s}\left(T_{m}\right)}=\frac{R H_{a} * P_{s}\left(T_{a}\right)}{P_{s}\left(T_{m}\right)}
\end{gathered}
$$

where $R H_{a}$ is the ambient relative humidity, $P_{w}$ is the partial water vapour pressure of the atmosphere, and $P_{s}\left(T_{a}\right)$ and $P_{s}\left(T_{m}\right)$ are saturated water vapour pressure at ambient temperature $\left(T_{a}\right)$ and module temperature $\left(T_{m}\right)$, respectively. The calculations of saturated and absolute water vapour pressure of the atmosphere are made according to the standard BS 1339-1:2002 [28]:

$$
\begin{gathered}
P_{s}=f * P_{s}{ }^{\prime} \\
P_{w}=R H * P_{s}=R H * f * P_{s}{ }^{\prime}
\end{gathered}
$$

where $P_{s}^{\prime}$ is the pure saturation vapour pressure at a given temperature, $P_{s}$ is the saturated vapour pressure in the air, $f$ is an enhancement factor to transfer $P_{s}{ }^{\prime}$ to $P_{s}$ and $P_{w}$ is the partial pressure of water vapour in the air. As both $P_{s}$ ' and $f$ are functions of temperature, $P_{s}$ and $P_{w}$ are also dependent on temperature. Figure 10 shows the actual water vapour pressure $\left(P_{w}\right)$ curve versus temperature at different relative humidity levels from $45 \%$ to $100 \%$. The relationship is straightforward to calculate but introduces an exponential relationship between water vapour pressure and temperature. An outdoor environment condition of $45 \% \mathrm{RH}$ and $35^{\circ} \mathrm{C}$ will result in an ambient water vapour pressure of $2.5 \mathrm{KPa}$. But at the same relative humidity level with a higher temperature of $85^{\circ} \mathrm{C}$ used in this study, the water vapour pressure will increase to 26. $2 \mathrm{KPa}$, which is almost 10 times that of the outdoor condition. Similarly, if assuming that the module temperature of an outdoor-installed PV module can reach $85^{\circ} \mathrm{C}$, the saturated water vapour pressure at the surface of the back sheet can be much higher than that at ambient temperature. Therefore, the differences between ambient relative humidity and module surface relative humidity induced by differences between $T_{a}$ and $T_{m}$ need to be considered when describing the stresses experienced by the module. Substituting Eqns (5) and (6) into Eqn (4), the relative humidity at the surface of the back sheet can be written as follows:

$$
R H_{m}=\frac{P_{w}}{P_{s}\left(T_{m}\right)}=\frac{R H_{a} * f\left(T_{a}\right) * P_{s}{ }^{\prime}\left(T_{a}\right)}{f\left(T_{m}\right) * P_{s}{ }^{\prime}\left(T_{m}\right)}
$$

where $P_{s}^{\prime}\left(T_{a}\right)$ and $P_{s}^{\prime}\left(T_{m}\right)$ are saturated water vapour pressure of pure water at ambient temperature $T_{a}$ and module temperature $T_{m}$, and $f\left(T_{a}\right)$ and $f\left(T_{m}\right)$ are relative enhancement factors at $T_{a}$ and $T_{m}$. For outdoor exposure, module temperature is often different from ambient temperate because of irradiance, wind speed, installation method, heat exchange with the environment and the condition of the sky and so on. As stated earlier, in laboratorybased damp-heat tests, $T_{a}$ equals $T_{m}$; that is, relative surface humidity of the back sheet simply becomes ambient relative humidity:

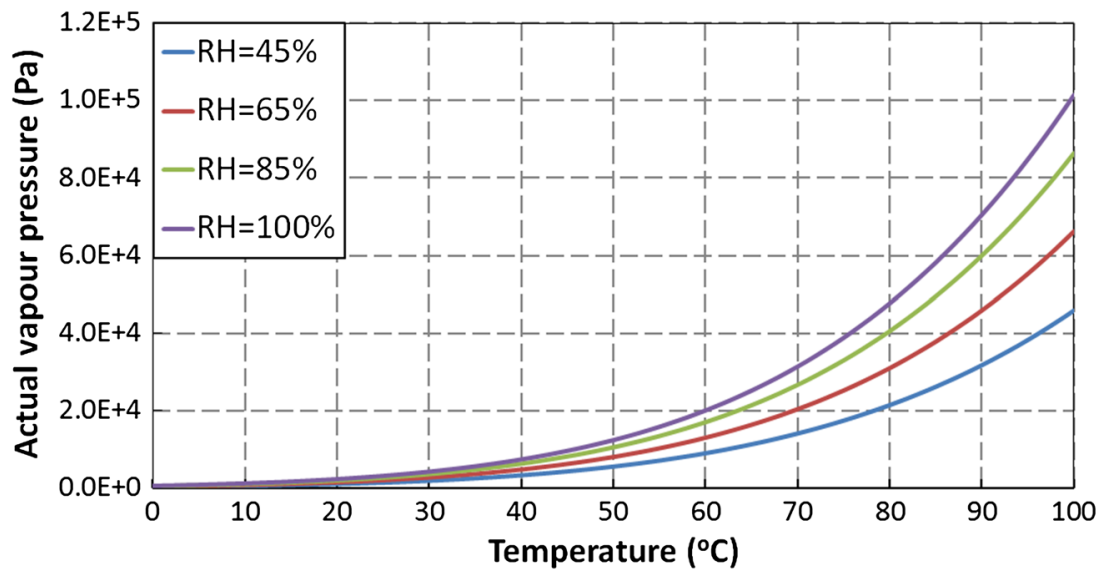

Figure 10. Actual water vapour pressure versus temperature. 


$$
R H_{m}=R H_{a}
$$

A humidity dose model can then be established to quantify the effective cumulative stresses imposed on the module within certain time duration that contribute to the degradation process. In what follows, assumptions are made that the loss of adhesion is a process depending on module micro-climatic conditions and is independent of the state of the module. The latter clearly is a simplification, as in reality modules will oscillate between drying out and absorbing humidity. However, in the case of laboratory tests, the steady state experiments simplify understanding and provide the necessary groundwork insight into the effects of humidity on adhesion. The micro-climatic relative surface humidity of the back sheet $\left(R H_{m}\right)$ is considered as the dominating driving factor while module temperature is considered an accelerating factor that can be modelled using an Arrhenius function. The Arrhenius form is a commonly used acceleration model defining the relationship between degradation and temperature when a single mechanism dominates the ageing process [29-32]. This allows the development of a model to describe stresses in different operating environments. A cumulative function of time with relative surface humidity of the back sheet and module temperature as weighting factors within time duration of $\Delta t$ can be established as follows:

$$
\text { dose }=R H_{m} e^{-\frac{E_{a}}{R T_{m}}} \Delta t
$$

where $E_{a}$ is the activation energy of the degradation process, $R$ is the gas constant $(8.314 \mathrm{~J} /(\mathrm{K} \mathrm{mol}))$ or Boltzmann's constant $\left(8.617 \times 10^{-5} \mathrm{eV} / \mathrm{K}\right)$ depending on the units and $T_{m}$ is the absolute module temperature in kelvin. Considering the postulated $R H_{m}$ in Eqns (7) and (8), the humidity dose for the tests in this study can be written as follows:

$$
\begin{aligned}
\text { dose } & =R H_{m} e^{-\frac{E_{a}}{R T_{m}}} \Delta t=\frac{R H_{a} * f\left(T_{a}\right) * P_{s}^{\prime}\left(T_{a}\right)}{f\left(T_{m}\right) * P_{s}^{\prime}\left(T_{m}\right)} e^{-\frac{E_{a}}{R T_{m}}} \Delta t \\
& =R H_{a} e^{-\frac{E_{a}}{R T_{m}}} \Delta t
\end{aligned}
$$

This model implies that it is not the ambient humidity but the relative surface humidity of the back sheet that is the most important driving factor for moisture ingress. It considers the influences of module temperature on micro-climatic humidity. However, this dose model is only responsible for degradation induced by humidity and may only apply to limited temperature and humidity levels. The key descriptor required for the prediction of ageing is the activation energy, which is determined in the next section.

\subsection{Degradation of adhesion strength and humidity dose}

It is believed that the degradation of adhesion strength increases with increasing humidity dose, but whether its form is linear, exponential, power or logarithmic is unknown. Here, we investigated two approaches, that is, starting from the conventional linear and then extending to exponential degradation model. For each scenario, the activation energy is calculated, and the relationship between adhesion degradation and humidity dose is discussed.

\section{(a) Linear model}

The linear model is the simplest degradation model that assumes the adhesion strength degradation $(\Delta S)$ to be directly proportional to humidity dose:

$$
\begin{gathered}
\Delta S=k^{*} \text { dose }=k R H_{a} e^{-\frac{E_{a}}{R T_{m}}} \Delta t \\
R_{D}=\frac{\Delta S}{\Delta t}=k R H_{a} e^{-\frac{E_{a}}{R T_{m}}}
\end{gathered}
$$

This enables the extraction of $E_{a}$ by taking the natural logarithm of the degradation rate $\left(R_{D}\right)$ and the reciprocal of $T_{m}$, which will generate an Arrhenius plot:

$$
\ln \frac{\Delta S}{\Delta t}=-\frac{E_{a}}{R} \frac{1}{T_{m}}+\ln \left(k R H_{a}\right)
$$

Figure 11 shows the Arrhenius plot results for this study at a constant $R H_{a}$ of $85 \%$ but varying $T_{m}$ of 95,85 and $65^{\circ}$ C. The average $R_{D}$ at each of the three testing conditions was used to obtain the plot. A linear relationship is observable, and its slope allows the determination of $E_{a}$ :

$$
\begin{gathered}
\text { slope }=-\frac{E_{a}}{R}=-6466 \\
E_{a} \cong 54 \mathrm{~kJ} / \mathrm{mol}=0.56 \mathrm{eV}
\end{gathered}
$$

With the activation energy calculated, the proposed humidity dose in Eqn (10) can be computed for all the five humidity and temperature conditions listed in Table I. The adhesion strength degradation shown in Figure 6 can then be re-investigated as dependent on the humidity dose, and the results are plotted in Figure 12. According to the defined linear degradation model in Eqn (11), adhesion

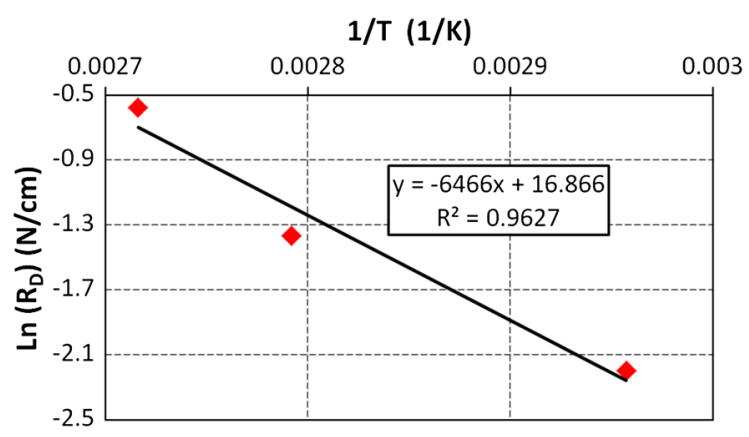

Figure 11. Arrhenius plot between natural logarithm of degradation rates and the inverse of absolute module temperature. 


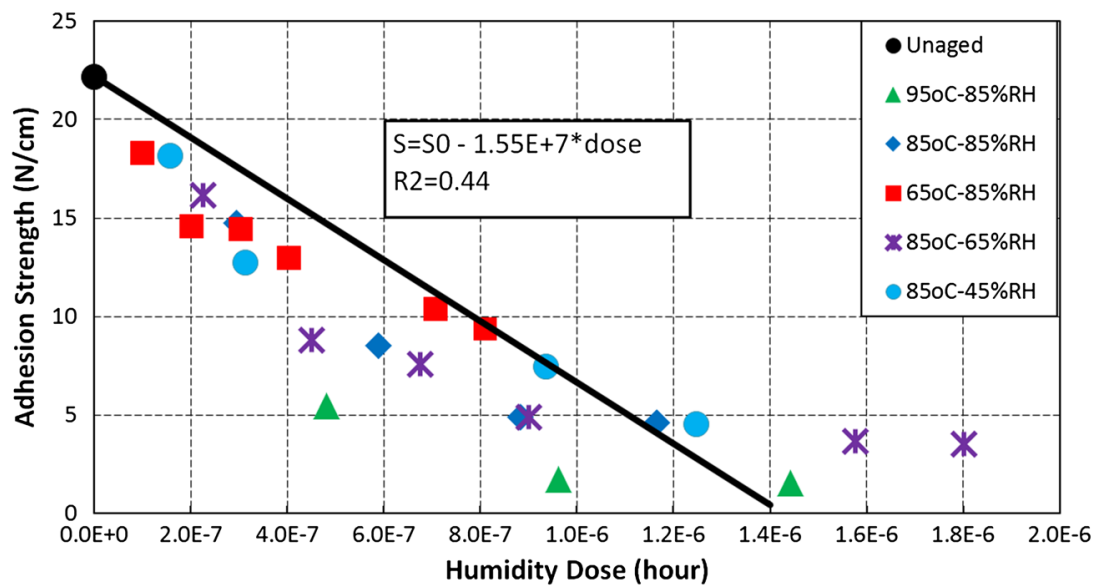

Figure 12. Degradation of adhesion strength versus humidity dose using activation energy calculated from linear model.

strength after a certain degradation time $\left(S_{t}\right)$ should be

$$
S_{t}=S_{0}-\Delta \mathrm{S}=S_{0}-k * \text { dose }=S_{0}-k R H_{a} e^{-\frac{E_{a}}{R T_{m}} \Delta \mathrm{t}}
$$

However, it is seen from Figure 12 that the adhesion strength does not follow the conventional linear approximation, instead showing a good match to exponential decay. This implies that the linear form does not suit the degradation well, and an exponential model may better represent the degradation, which is illustrated in scenario (b). The divergences between the proposed model and the experimental data may result from the assumption that constant degradation exists throughout the whole ageing procedure, which in reality is a decelerating process. The use of an average $R_{D}$ value hid the detailed features of degradation.

\section{(b) Exponential model}

By the enlightenment of Figure 12, an exponential model can be established to describe the correlation between adhesion strength and humidity dose during degradation:

$$
S_{t}=S_{0} e^{-k * \text { dose }}=S_{0} \mathrm{e}^{-k * R H_{a} * e^{-\frac{E_{a}}{R T_{m}}} * \Delta t}
$$

Equation (17) can be restructured by moving $S_{0}$ to the left side of the equation and taking the natural logarithm of both sides twice:

$$
\ln \left(-\ln \left(\frac{S_{t}}{S_{0}}\right)\right)=-\frac{E_{a}}{R} \frac{1}{T_{m}}+\ln \left(k * R H_{a} * \Delta t\right)
$$

By plotting $\ln \left(-\ln \left(S_{t} / S_{0}\right)\right)$ versus $1 / T_{m}$, straight lines can be obtained whereby $E_{a} / R$ determines the slope of the curve, and the combined parameter of $\left(k * R H_{a} * \Delta t\right)$ determines the intercept. In principle, at a constant $R H_{a}$ but varying $T_{m}$, parallel lines with the same slope and different intercepts can be obtained at different degradation times. Figure 13 shows such curves at an $\mathrm{RH}_{a}$ of $85 \%$ but varying temperatures of
95,85 and $65^{\circ} \mathrm{C}$ at degradation times of 24,48 and $72 \mathrm{~h}$, respectively. The three data sets can all be fitted with straight lines, although two of them at degradation times of 24 and $48 \mathrm{~h}$ show some divergences. This may be because at the beginning of ageing, degradation is a bit faster than the proposed exponential decay model. Another important source of divergences is the variation result from experiment especially for the peel tests that are destructive. The reason why we choose the data at these three time slots is because it approaches the lowest detectable threshold of the adhesion strength for the condition at $95^{\circ} \mathrm{C} / 85 \% \mathrm{RH}$, and degradation results at longer exposure time are meaningless at this condition. The $95{ }^{\circ} \mathrm{C} / 85 \% \mathrm{RH}$ condition is one of the three temperature regimes used to calculate the activation energy. The three lines are almost parallel with each other, indicating a similar slope. Taking the average slope of the three fitted curves gives an activation energy of $63 \mathrm{~kJ} / \mathrm{mol}(0.65 \mathrm{eV})$.

As for the linear model, the adhesion strength versus humidity dose is investigated for the exponential model with the results shown in Figure 14. The five curves in Figure 6 have been normalised by dose, and a strong exponential agreement between adhesion strength and humidity dose is evident, which can be approximated as follows:

$$
S_{t}=\mathrm{S}_{0} e^{-3.28 * 10^{7} * \text { dose }}
$$

The fitted coefficient of determination is over 0.92, which means highly correlated. This verifies the suitability of exponential model to describe the correlation between adhesion strength and humidity dose.

The degradation may be caused by multiple mechanisms and may follow Eqns (10) and (19) over only limited temperature and humidity ranges. In Figure 14, data at $95^{\circ} \mathrm{C} / 85 \% \mathrm{RH}$ show some divergences from the fitted curve, which indicates that some other unaccounted-for degradation mechanisms may have been triggered or are becoming increasingly important at this high temperature. A temperature of $95^{\circ} \mathrm{C}$ is much higher than the melting point of EVA, which is around $40-70^{\circ} \mathrm{C}$ (lower 


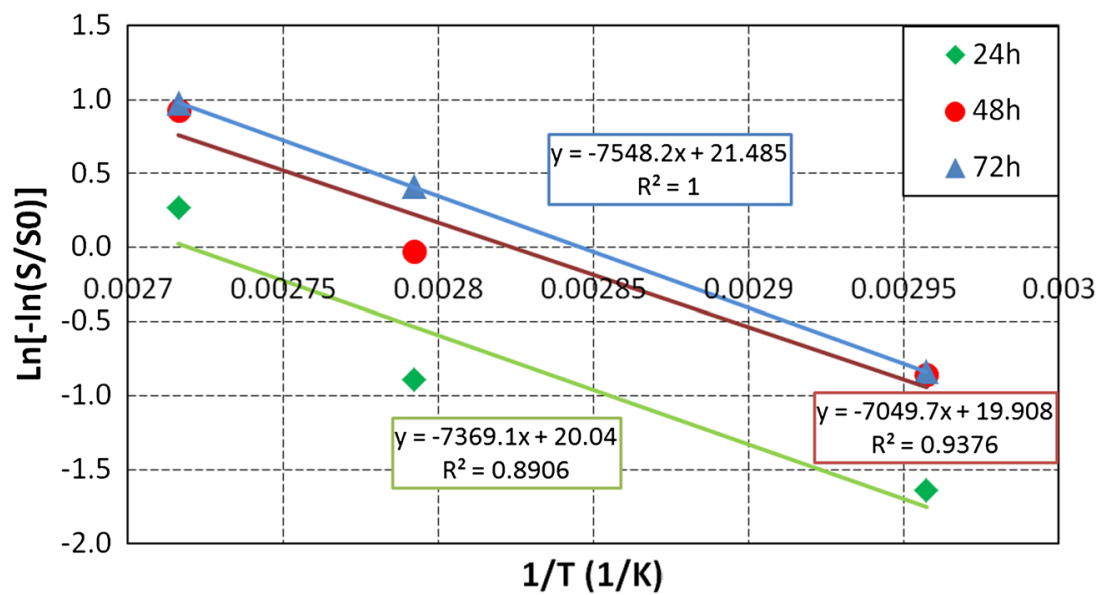

Figure 13. Plot of $\ln \left(-\ln \left(S_{t} / S_{0}\right)\right)$ against inverse of absolute module temperature at degradation times of 24,48 and $72 \mathrm{~h}$ for exposures at $95{ }^{\circ} \mathrm{C} / 85 \% \mathrm{RH}, 85^{\circ} \mathrm{C} / 85 \% \mathrm{RH}$ and $65^{\circ} \mathrm{C} / 85 \% \mathrm{RH}$.

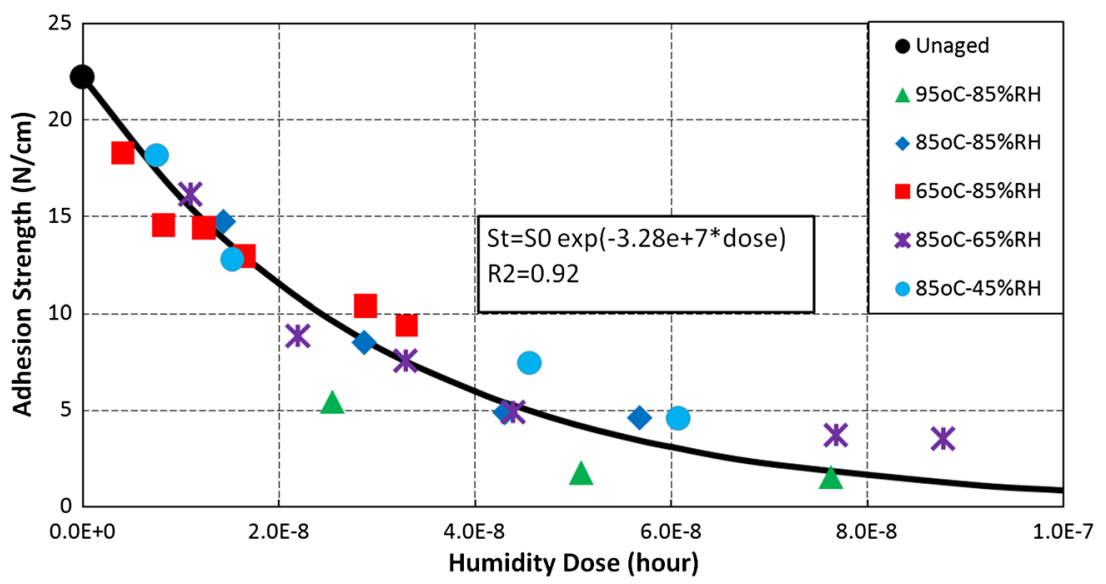

Figure 14. Degradation of adhesion strength versus humidity dose with activation energy calculated from exponential model.

values are attributed to the melting of less perfect crystals, and a higher melting point represents the melting of the primary crystals in EVA) so that the polymer may have experienced structural and morphology changes, resulting in different degradation mechanisms [33,34]. However, the data at $95{ }^{\circ} \mathrm{C} / 85 \% \mathrm{RH}$ in Figure 14 are not so far away from the model, which suggests that the primary degradation mechanism is still humidity even at this high temperature condition.

The results show the adhesion strength dependence on cumulative stresses experienced by a PV module within a certain damp-heat degradation period can be modelled by an exponential function through the proposed humidity dose definition. The conventional linear degradation model failed to describe this relationship. Issues such as degradation induced by other stress factors and the response to cyclic changes in environmental conditions need further research before a generic outdoor degradation prediction can be made, but the presented work represents a step towards this goal.

\section{CONCLUSIONS}

The durability of adhesion between the back sheet and encapsulant for commercial crystalline silicone minimodules to withstand the effects of humidity ingress has been investigated. This was achieved by exposing the devices to different stress levels of humidity at different temperatures. It is shown that the loss of adhesion varied significantly under the different regimes. Under these conditions, humidity is the primary driver of the reduction of adhesion strength, and temperature determines the speed of degradation. Linking this particular stress mechanism to other operating environments can be carried out by developing a stress dose model to describe the cumulative stresses imposed on PV modules and investigating the relationship between degradation and the dose. In this research, a humidity dose is defined by assuming the relative surface humidity at the back sheet as the main driving factor and module temperature as the accelerant with an Arrhenius influence of the degradation process. The 
calculation of relative surface humidity of the back sheet transfers the environmental humidity to module surface humidity and considers the influence of module temperature on the effective humidity at the surface of the back sheet. This approach enables modelling of the loss of adhesion due to humidity ingress with humidity dose, which demonstrates an exponential relationship.

This is the first step of modelling the loss of adhesion in realistic outdoor operation, where devices experience not only constant humidity but also varying humidity, cyclic temperature and photochemical reactions. Further work is needed to quantify additional effects from the other stresses and the combination of these factors before developing a full degradation model of PV module in different environments, but this can only be achieved on a mechanism-by-mechanism level and built up to an effective overall model. The link between adhesion strength or, more generally, encapsulant state and actual device performance and safety is still a goal that requires significant additional amounts of research.

\section{ACKNOWLEDGEMENTS}

This work has been supported by a joint UK-India initiative in solar energy through a joint project 'Stability and Performance of Photovoltaics (STAPP)' funded by the Research Councils UK (RCUK) Energy Programme (contract no: EP/H040331/1) and by the Department of Science and Technology (DST) in India.

\section{REFERENCES}

1. Quintana MA, King DL, McMahon TJ, Osterwald CR. Commonly observed degradation in field-aged photovoltaic modules. 29th IEEE PVSEC New Orleans, USA, 2002.

2. Pern J. Module encapsulation materials, processing and testing. APP International PV Reliability Workshop, Shanghai, China, 2008.

3. del Cueto JA, McMahon TJ. Analysis of leakage currents in photovoltaic modules under high-voltage bias in the field. Progress in Photovoltaics: Research and Applications 2002; 10: 15-28.

4. Sanchez-Friera P, Piliougine M, Pelaez J, Carretero J, Sidrach de Cardona M.. Analysis of degradation mechanisms of crystalline silicon PV modules after 12 years of operation in Southern Europe. Progress in Photovoltaics: Research and Applications 2011; 19: 658666.

5. Polverini D, Field M, Dunlop E, Zaaiman W. Polycrystalline silicon PV modules performance and degradation over 20 years. Progress in Photovoltaics: Research and Applications 2012; 21: 1004-1015.
6. Chamberlin CE, Rocheleau MA, Marshall MW, Reis AM, Coleman NT, Lehman PA. Comparison of PV module performance before and after 11 and 20 years of field exposure, 37th IEEE PV Specialists Conference 2011, Seattle, WA.

7. Saly M, Ruzinsky M, Redi P. Accelerated testing of small photovoltaic modules and encapsulants at elevated voltage, temperature and humidity. 17th EUPVSEC 22-26, Munich, Germany, 2001.

8. McIntosh KR, Powell NE, Norris AW, Cotsell JN, Ketola BM. The effect of damp-heat and UV aging tests on the optical properties of silicone and EVA encapsulants. Progress in Photovoltaics: Research and Applications 2010; 19: 294-300.

9. IEC 61215, crystalline silicon terrestrial photovoltaic (PV) modules-design qualification and type approval, 2005.

10. IEC 61646, Thin-film terrestrial photovoltaic (PV) modules-Design qualification and type approval, 2008.

11. Kempe M. Overview of scientific issues involved in selection of polymers for PV application. 37th IEEE PV Specialists Conference 2011, Seattle, WA.

12. Comyn J. Adhesion Science. The Royal Society of Chemistry: Cambridge, UK, 1997.

13. Svorcik V, Ekrt O, Rybka V. Permittivity of polyethylene and polyethyleneterephtalate. Journal of Materials Science Letters 2000; 19: 1843-1845.

14. Ferguson TP, Qu J. An engineering model for moisture degradation of polymer/metal interfacial fracture toughness. IEEE International Symposium on Advanced Packaging Materials: Processes, Properties and Interfaces 2005.

15. Kempe MD. Modelling of rates of moisture ingress into photovoltaic modules. Solar Energy Materials \& Solar Cells 2006; 90: 2720-2738.

16. Kapur J, Proost K, Smith CA. Determination of moisture ingress through various encapsulants in glass/ glass laminates. 34th IEEE Photovoltaic Specialists Conference, Philadelphia, PA, USA, 2009.

17. McMahon TJ, Jorgensen G.. Adhesion and thin-film module reliability, Proceedings of the 4th World Conference on PV Energy Conversion, Waikoloa, Hawaii, USA, 2006; 2062-2065.

18. Pern FJ, Glick SH. Adhesion strength study of EVA encapsulants on glass substrates. National Center for Photovoltaics and Solar Program Review Meeting 2003, Denver, Colorado.

19. Pern FJ, Jorgensen GJ. Enhanced adhesion of EVA laminates to primed glass substrates subjected to damp heat exposure, 31st IEEE Photovoltaics Specialists Conference and Exhibition 2005, Lake Buena Vista, Florida. 
20. BS EN 28510-1:1993, ISO8510-1:1990, Adhesivespeel test for a flexible-bonded-to-rigid test specimen assembly-Part 1: $90^{\circ}$ peel.

21. Machovie V, Andertova J, Kopecky L, Eerny M, Borecka L, Poibyl O, Kolao F, Svitilova J. Effect of aging of PET fibre on the mechanical properties of PET fibre reinforced cement composite. Ceramics 2008; 52(3):172-182.

22. Andanson JM, Kazarian SG. In situ ATR-FTIR spectroscopy of poly(ethylene terephthalate) subjected to high-temperature methanol. Macromolecular Symposia 2008; 265: 195-204.

23. Sammon C, Yarwood J, Everall N. A FTIR-ATR study of liquid diffusion processes in PET films: comparison of water with simple alcohols. Polymer 2000; 41: 2521-2534.

24. Koehl M, Heck M, Wiesmeier S, Wirth J. Modeling of the nominal operating cell temperature based on outdoor weathering. Solar Energy Materials \& Solar Cells 2011; 95: 1638-1646.

25. Alonso Garcia MC, Balenzategui JL. Estimation of photovoltaic module yearly temperature and performance based on nominal operation cell temperature calculations. Renewable Energy 2004; 29: 1997-2010.

26. King DL, Boyson WE, Kratochvil JA. Photovoltaic Array Performance Model. United States Department of Energy: Washingtion, (DC), 2004.

27. Koehl M, Heck M, Wiesmeier S. Modelling of conditions for accelerated lifetime testing of humidity impact on PV-modules based on monitoring of climatic data. Solar Energy Materials \& Solar Cells 2012; 99: 282-291.

28. BS 1339-1:2002, Humidity-part 1: terms, definitions and formulae, 2002.

29. Kurtz S, Miller D, Kempe M, Bosco N, Whitefield K, Wohlgemuth J, Dhere N, Zgonena T. Evaluation of high-temperature exposure of photovoltaic modules. Progress in Photovoltaics: Research and Applications 2011; 19:954-965.

30. Gorjian N, Ma L, Mittinty M, Yarlagadda P, Sun Y. A review on degradation models in reliability analysis. $4^{\text {th }}$ World Congress on Engineering Asset Management 28-30 September, Athens, Greece, 2009.

31. Koehl M. Durability of PV modules: performance over time or time to failure. PV Module Reliability Workshop, Berlin, Germany, 2011.

32. Lam DCC, Yang F, Tong P. Chemical kinetic model of interfacial degradation of adhesive joints. IEEE Transaction on components and packaging technology 1999; 22: 44-48.

33. Xia ZY, Cunningham DW, Wohlgemuth JH. A nonsolvent extraction method for measuring gel content of ethylene vinyl, 34th IEEE Photovoltaic Specialists Conference, Philadelphia, PA, USA, 2009.

34. Li HY, Perret-Aebi LE, Theron R, Ballif C, Luo Y, Lange RFM. Towards in-line determination of EVA Gel content during PV modules lamination processes, 25th European Photovoltaic Solar Energy Conference and Exhibition, Valencia, Spain, 2010. 